\title{
PREDICTION OF RESIDUAL STRENGTH OF COMPOSITE COLUMNS USING FEM ANALYSIS
}

\author{
Sun-Hee Kim ${ }^{\text {a }}$, Kyong-Soo Yom ${ }^{\mathrm{b}}$, Sung-Mo Choi ${ }^{\mathrm{a}}$ \\ ${ }^{\text {a }}$ University of Seoul, Department of Archtecture and Archtectural Engineering, Korea \\ ${ }^{\mathrm{b}}$ Harmony Structural Engineering, Seoul, Koea
}

\begin{abstract}
Fires in buildings cause not only economic losses but also many casualties. A prolonged fire involves the possibility of the damage to structural members, which calls for the repair or reinforcement of the building. Since it is critical to decide whether structural members need reinforcement, the technique to determine the degree of the damage to structural members caused by a fire should be established. CFT columns are superior to generic steel columns in terms of fire resistance performance thanks to the thermal storage effect of the concrete inside the columns. Studies have suggested how to reinforce the concrete to further improve the structural strength and fire resistance performance of CFT columns. When CFT columns of a building are damaged by a fire, it is required to determine preciously how serious the structural deterioration of the members is. The purpose of this study is to evaluate the residual strength of CFT columns damaged by a fire by evaluating the temperature distribution inside the columns and determining the degree of deterioration in the load capacity of concrete and steel in relation to temperature distribution.
\end{abstract}

Keywords: residual strength, composite columns, thermal stress, heat transfer, FEM

\section{INTRODUCTION}

Fires at multi-purpose buildings or those that many people use in particular occur frequently, which causes both economic losses and casualties. As various construction materials are used to fit the purposes of the buildings including combustibles, fires tend to last long. When construction members are exposed to high temperatures for prolonged hours, the area of damage extends. Damage index needs to be identified before repair and reinforcement. Because identifying the need for repair and reinforcement is as important as preventing fires, reliable techniques for it should be established. However, the measure for structural evaluation after a fire and the guideline for repair and reinforcement in accordance with damage index are not available. This study suggests evaluating the residual strength of composite columns after a fire by evaluating temperature distribution and identifying the degree of deterioration in the load capacity of concrete and steel. Having higher tolerance for loads than other composite columns, CFT columns are frequently used in special-purpose buildings which require high compressive strength and long-span structure. Analytical studies and experiments conducted in Korea and overseas have verified that CFT columns have better fire-resistance performance than steel columns. Nevertheless, CFT columns are exposed to potential damages when a fire occurs. Therefore, the damage to and behaviour of the columns should be assessed.

\section{MECHANICAL PROPERTIES OF CONCRETE AND STEEL AFTER A FIRE}

The Japan Concrete Institute (2000) provides critical temperatures for concrete $\left(250 \sim 380^{\circ} \mathrm{C}\right)$ and steel $\left(250 \sim 380^{\circ} \mathrm{C}\right)$.

\subsection{Concrete}

Although concrete is fire-proofing, its texture goes slack and loses original properties upon temperature rise because it is made of the mixture of water, aggregate and cement which is formed into a hard matrix. The material properties and colour of concrete also change as temperature goes up. The hydrothermal temperature of concrete can be estimated by its colour because it turns pink 
at 300 600 Celsius degree, light gray at 600 950 celsius degree and flaxen at temperatures above it. Temperatures above 400 celsius degree cause tiny cracks in cement paste and those above 600 celsius degree trigger cracks in the boundary between cement and aggregate. Concrete cracks seriously if the temperature reaches 800 celsius degree. Starting to decline rapidly when exposed to temperatures over 400 celsius degree for more than 1 hour, the strength of concrete is almost lost at over 800 celsius degree. If the temperature does not rise very high at a fire, concrete strength is restored. It is restored up to $90 \%$ of initial strength in a year if the temperature is 500 celsius degree or below. The deterioration in compressive strength is significant in high-strength concrete in particular when it is exposed to high temperatures. The compressive strength of concrete is restored as shown in figure 1. If the hydrothermal temperature of concrete is below 500 celsius degree, compressive strength is restored to reusable level.

In general, the tensile strength of concrete is not a major consideration in structural design. But, it is a critical factor at high temperatures due to the concentration of thermal stress. Because tensile strength is more easily affected by internal defects than compressive strength, it is more subject to heat. Tensile strength declines rapidly when the temperature rises over 250 celsius degree.

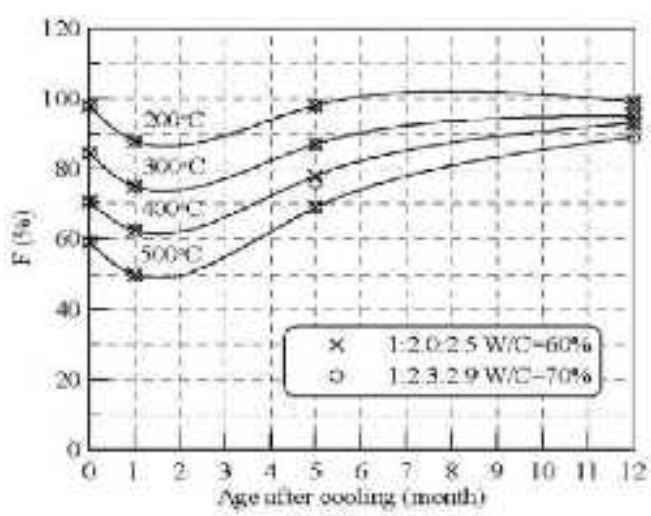

Fig. 1 Restoration of heated concrete's compressive strength

\subsection{Steel}

Although the change in the structural performance of steel induced by heat varies depending on steel type, it is a safe assumption that the yield point of steel becomes unclear when the temperature is over 720 celsius degree. Studies have found that the strength of steel exposed to temperatures below 600 celsius degree is restored to its original level. Therefore, 600 celsius degree is the threshold which decides whether the steel can be reused. It is melted or decomposed when exposed to temperatures over 600 celsius degree. The thermal expansion of steel is expressed as a linear equation or a two-dimensional linear equation in temperature and strain. The bonding performance of steel deteriorates gradually as temperature rises mainly because of the cracks in concrete and the deterioration in concrete strength. It is reported that the bonding performance of steel is almost fully exhausted at the temperatures over 600 celsius degree (ITA 2004). In fire resistance design involving fire resistance steel, the type of fire, the temperature of steel frame and the prediction of structural deformation is considered in deciding fire-proofing materials for structural members to provide rational and economically-efficient outcome. Fire resistance steel is manufactured by adding molybdenum, niobium and boron to steel and decreasing carbon and manganese to adjust grain size and improve quenching properties for improving load capacity at high temperatures. Fire resistance steel also has improved load capacity at normal temperatures and enhanced weldability. As shown in figure 2, fire resistance steel is superior to general steel by approximately $30 \%$ in terms of the resistance to high temperatures. It is reported that the load capacity of the steel at 600 celsius degree is two-thirds of that at normal temperatures. 


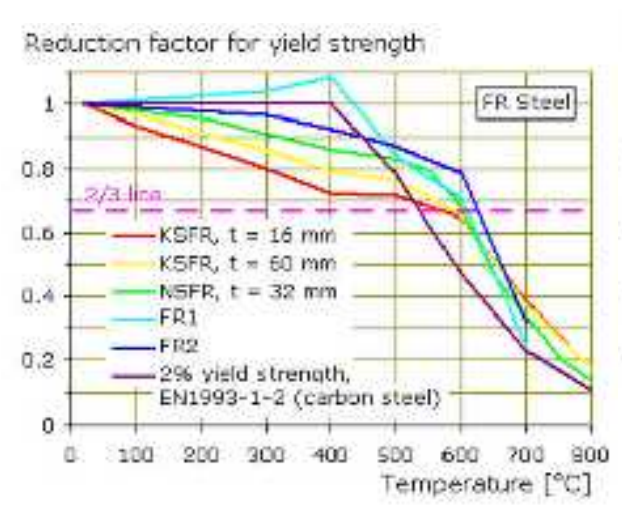

(a) Yield strength

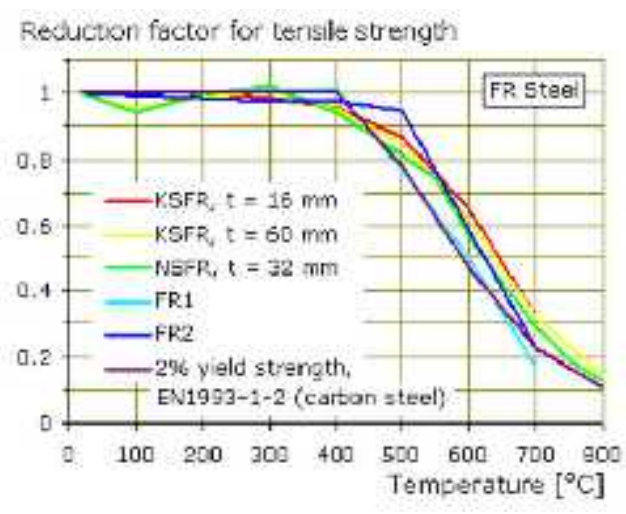

(b) Tensile strength

Fig. 2 Yield strength \& tensile strength of FR steel after a fire

\section{EVALUATION OF RESIDUAL STRENGTH OF CFT COLUMNS}

The technique and materials for repair and reinforcement should be decided based on the applicability of the technique, structural safety and economic-efficiency. The causes of structural defects should be analyzed precisely in the process. The appraisal of current condition and evaluation of safety should be conducted before the necessity, method and level of repair and reinforcement are decided. Residual strength index is used to evaluate the load capacity of structural members. The residual strength index for CFT columns is defined as the load capacity after a fire divided by that before a fire.

Although studies on residual strength index have been conducted in Korea and overseas, it is hardly used because of some reasons. First, residual strength indexes for composite columns suggested in the studies have very narrow coverage and do not yield practical comparison/application. Second, the results obtained from reduced-size specimens involve the possibility of overestimation when applied to full-scale structures. Third, the same boundary conditions need to be provided when the comparison of strength before and after a fire is made for the evaluation of residual strength. However, providing the same conditions is feasible only in analysis. In short, the difference between specimens and actual structures makes it impractical to decide whether repair and reinforcement works are required based on residual strength. The evaluation of residual strength should be approached from various angles.

\subsection{Studies in Korea}

Gyu-yong Kim (2009) conducted a study on the prediction of the residual strength of unprotected CFT columns using unloaded heating tests. He used temperature distribution inside the columns and the decrease in material strength caused by high temperatures in order to predict overall sectional strength. Boundary coefficient was applied in the analysis of concrete whose compressive strength was 40, 60 and $80 \mathrm{MPa}$.

Sung-mo Choi (2011) conducted an experimental study on the residual strength of CFT columns using the cross-sectional shape of the columns as a variable. He analyzed the ratio of load capacity reduction and the temperatures and behaviors of the columns in relation to the variable. He also compared the equations prescribed in countries' construction codes. Figure 3 shows loaddisplacement relation of the CFT columns before and after a fire. The behaviors of the CFT columns after a fire (black lines) are characterized by the indistinctness of ultimate strength sections. As observed from the graphs, load capacity deteriorated very gradually after ultimate strength. As shown in figure 3, the residual strength index of the square CFT column reinforced with steel bars and that reinforced with a square steel tube was 0.59 and 0.58 , respectively. The column reinforced with a circular steel tube showed the highest residual strength index of 0.72 . It is deemed that the loss of strength in the column was smaller because thermal stress was dispersed in different directions in the circular steel tube inside the column. 


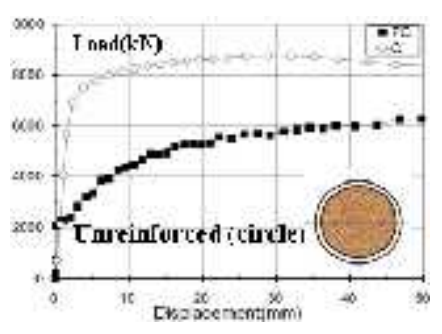

(a) Unreinforced circular column

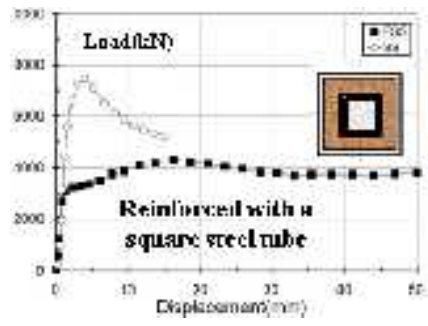

(d) Square column reinforced with a square steel tube

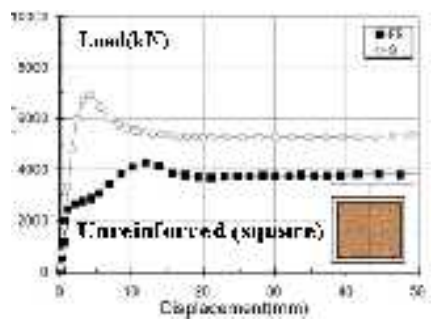

(b) Unreinforced square column

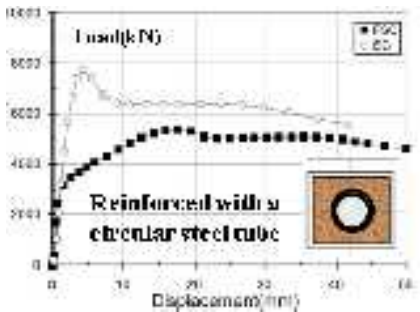

(e) Square column reinforced with a circular steel tube

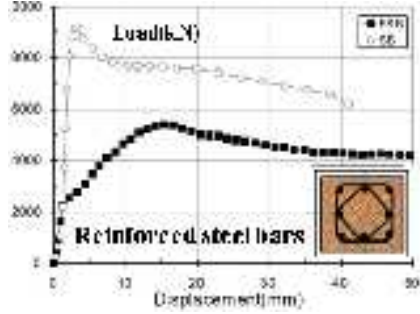

(c) Square column reinforced with steel bars

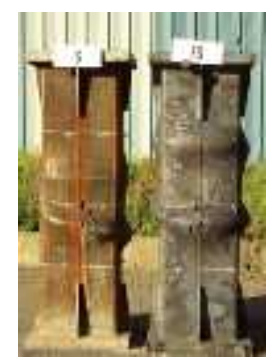

(f) Before \& after a fire (reinforced with steel bars)

Fig. 3 Load-displacement relation before \& after a fire

\subsection{Overseas studies}

Lin Hai Han (2003) conducted unloaded heating tests in a study to analyze the compressive behavior and flexural behavior of CFT columns after a fire. The residual strength index of circular CFT column and square CFT column which were exposed to high temperatures for 3 hours was 0.66 and 0.75 , respectively, which was higher than what was obtained from the studies conducted in Korea. It is deemed that the reduced-size specimens used in the test contributed to the overestimated result. Xin Yu (2009) also conducted a study to predict the residual strength of reinforced and unreinforced CFT columns. The residual strength of the columns obtained from his test was 0.6 on average as shown in figure 5.
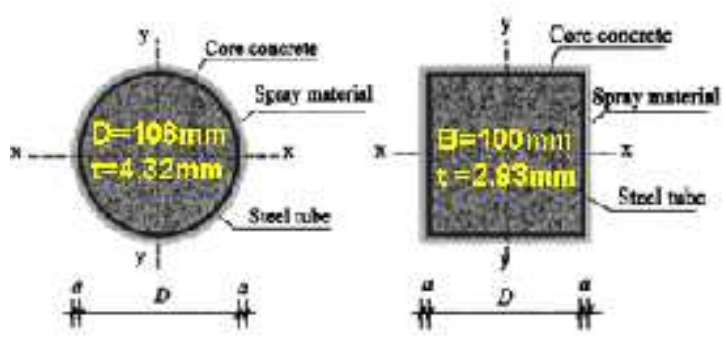

Fig. 4 Specimens in residual strength test

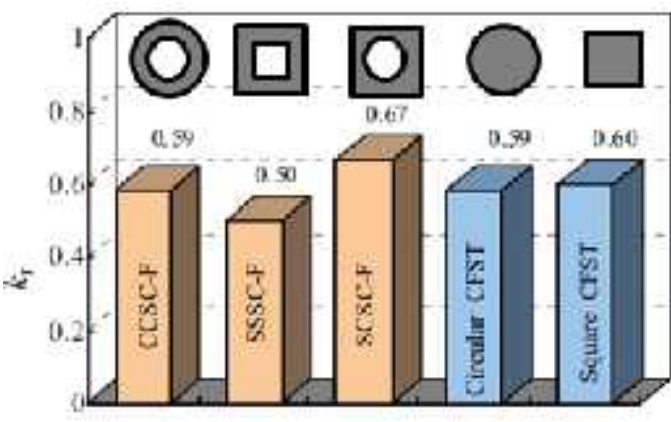

Fig.5 Residual strength indexes of CFT columns

\section{EVALUATION OF RESIDUAL STRENGTH USING FEM ANALYSIS}

\subsection{Overview}

Many studies have been conducted on the fire resistance performance of CFT circular and square columns. However, quantitative analysis should include the analysis of the difference in the behavior at a fire in relation to reinforcement ratio, aspect ratio, slenderness ratio and material strength. Therefore, the flow chart for FEM analysis to predict the residual strength of CFT columns was drawn as shown below. The analysis to evaluate the load capacity of the columns after a fire consisted of 3 steps: Heat transfer analysis, bucking analysis and simple load analysis by linking temperature distribution and buckling analysis data. 


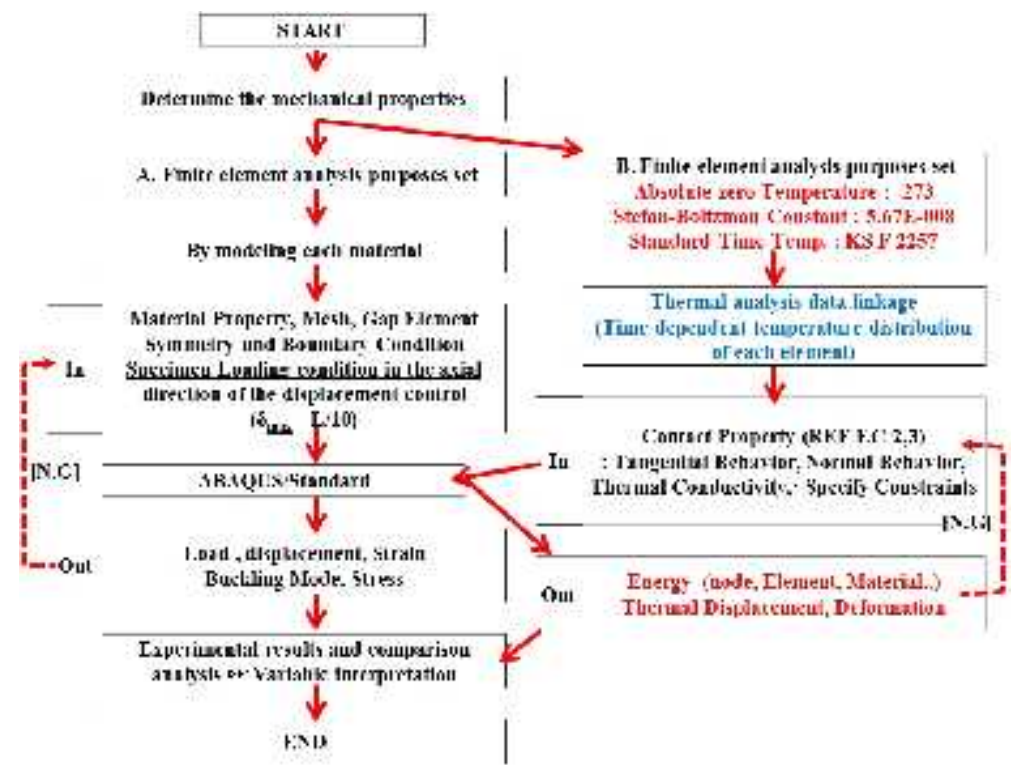

Fig. 6 Flow chart for FEM analysis

\subsection{Comparison between test and analysis results}

The analysis model for CFT columns was completed using ABAQUS 6.11 and compared with test result for verifying its reliability. Table 1 shows the results obtained from the test and analysis and figure 7 shows load-displacement relation. As shown in the table, initial stiffness and ultimate strength were higher in the test than in the analysis. The comparison of initial stiffness showed similarities, while irregular patterns were noticed in the comparison of ultimate strength.

Table 1. Comparison between test and analysis results

\begin{tabular}{c|c|c|c|c|c|c}
\hline \multirow{2}{*}{$\begin{array}{c}\text { Specimen/analysis } \\
\text { model }\end{array}$} & \multicolumn{3}{|c|}{ Initial stiffness $(\mathrm{kN} / \mathrm{mm})$} & \multicolumn{3}{c}{ Ultimate strength $(\mathrm{kN})$} \\
\cline { 2 - 7 } & Test & Analysis & Test/Analysis & Test & Analysis & Test/Analysis \\
\hline SN / ASN & 2780 & 2300 & $\mathbf{1 . 2 1}$ & 8,759 & 6984 & $\mathbf{1 . 2 5}$ \\
\hline CN / ACN & 3861 & 3341 & $\mathbf{1 . 1 6}$ & 6,954 & 7595 & $\mathbf{0 . 9 1}$ \\
\hline FSN /AFSN & 2854 & 2273 & $\mathbf{1 . 2 6}$ & 7,048 & 3598 & $\mathbf{1 . 9 5}$ \\
\hline FCN/AFCN & 2574 & 2020 & $\mathbf{1 . 2 6}$ & 4,284 & 3854 & $\mathbf{1 . 1 1}$ \\
\hline
\end{tabular}

The difference between the test and analysis results was more noticeable at high temperatures than in normal temperatures. It is because load capacity deteriorated after ultimate strength in the analysis, while yield point and ultimate strength were not clearly displayed in the test.

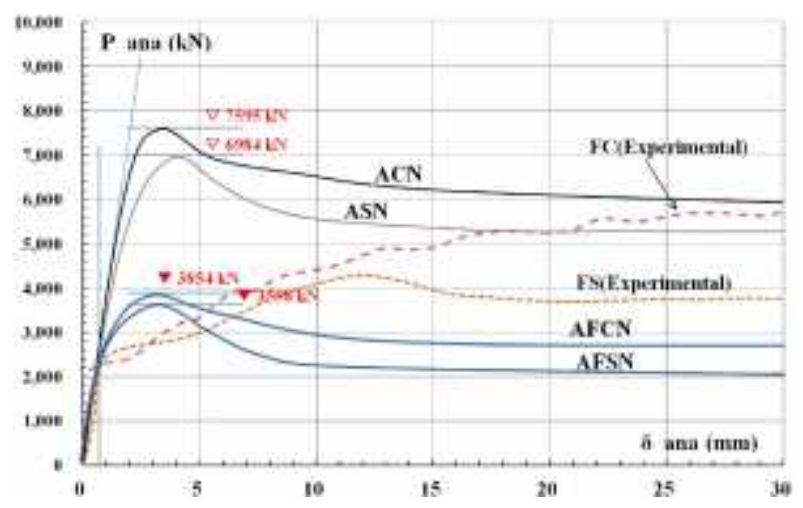

Fig 7 Load-displacement relation (FEM analysis) 


\subsection{Residual strength in relation to cross-sectional shape}

Figure 8 shows the decrease in the residual strength index of CFT columns. Residual strength index was higher in the columns reinforced with steel bars or a steel tube by approximately $20 \%$. The steel tube and steel bars inside the concrete maintained the original strength because thermal damage was minimal. Damaged areas were larger in square columns than in circular columns, seemingly because thermal stress was concentrated in the corners causing the deterioration of load capacity.

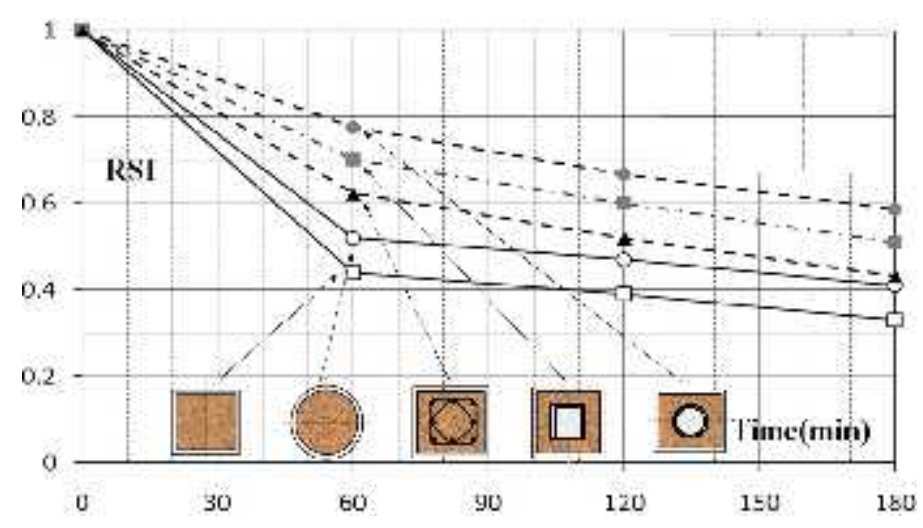

Fig.8 Residual strength index

\section{CONCLUSION}

Since the residual strength of composite columns is the index to measure the damage induced by a fire, the evaluation of residual strength should be made with adequate data. The criterion for deciding how to restore load capacity after a fire should also be established. The pattern of damage to a structure caused by a fire is an important factor in assessing the stability of the structure. Therefore, identifying the damage patterns of structural members forms the basis of the studies on fire resistance. Many studies have been conducted on the analysis/evaluation of the resilience of steel and concrete but it has yet to be considered in fire resistance design. Although the techniques for the repair/reinforcement after a fire have been developed, the evaluation of residual strength is not incorporated into the work in the field. Therefore, studies on the fire resistance performance and repair/reinforcement of composite structures should be conducted from various angles.

\section{ACKNOWLEDGMENTS}

This work was supported by the 2015 Conference and training support project at WISET (Center for Women in Science, Engineering and Technology).

\section{REFERENCES}

Lin-Hai Han et. al., 2002, Residual strength of concrete-filled RHS columns after exposure to the ISO-834 standard fire, Thin-Walled Structures, 40(12), p.991-1012.

Lin-Hai Han et. al., 2003, An experimental study and calculation on the fire resistance of concrete-filled SHS and RHS columns, Journal of Constructional Steel Research Journal of Constructional Steel Research, 59(4) p.427-452.

Lin-Hai Han et. al., 2006, Concrete-filled double skin steel tubular (CFDST) beam-columns subjected to cyclic bending, Engineering Structures, 28(12) p.1698-1714.

Hua Yang et. al., 2008, Effects of heating and loading histories on post-fire cooling behaviour of concretefilled steel tubular columns, Journal of Constructional Steel Research, 64(5) p.556-570.

Hui Lu et. al., 2010, Testing of self-consolidating concrete-filled double skin tubular stub columns exposed to fire Journal of Constructional Steel Research, 66(8-9), p.1069-1080.

Sun-Hee Kim, Yong-An Won and Sung-Mo Choi, 2012, A Study on the Evaluation of Residual Strength of Double Concrete Filled Tube Column by Unstressed test. Journal of Korean Society of Steel Construction. 24(1) pp81-89 